\title{
Cytokine production by human leukocytes with different expressions of natural antiviral immunity and the effect of antibodies against interferons and TNF- $\alpha$
}

\author{
Beata Orzechowska, Zenon Antoszków, Iwona Siemieniec, Maria Lorenc, \\ Bogna Jatczak and Zofia Błach-Olszewska
}

Institute of Immunology and Experimental Therapy, Polish Academy of Sciences, Wrocław, Poland

Received: 2006.09.08, Accepted: 2006.11.27, Published online first: 2007.03.20

\begin{abstract}
Introduction: Two activities of innate antiviral immunity were studied: the resistance of human peripheral blood mononuclear cells (PMBCs) ex vivo to viral infection and the production of cytokines.

Materials and Methods: Samples of blood were taken from healthy blood donors and from persons with frequent infections of the upper respiratory system. PMBCs were isolated by gradient centrifugation. Vesicular stomatitis virus (VSV) was used as the indicatory virus to infect PMBCs. The cytokines: IFN, TNF, and IL-6 were titrated by biological methods and IL-10 by ELISA.

Results: Blood donors were divided for two groups: those with VSV-resistant and those with VSV-sensitive PMBCs and secretion of cytokines by them was compared. The resistant PMBCs produced more cytokines than the sensitive ones. A statistically significant difference, was found only in the case of the IFNs. To examine the contribution of IFNs and TNF in maintaining resistance, leukocytes from both groups were treated with specific anti-cytokine antibodies. The authors' previous study showed that the elimination of spontaneous IFN- $\alpha$, IFN- $\beta$, IFN- $\gamma$, and TNF- $\alpha$ from resistant leukocytes resulted in increased VSV replication This indicates the important role of cytokines. In VSV-sensitive PMBCs, anti-IFN- $\alpha$ showed the opposite effect (decreased virus replication). In the absence of spontaneous IFN- $\alpha$, disturbances in cytokine production were observed.

Conclusions: Complete resistance of PMBC to VSV infection is accompanied by higher cytokine release, The paradoxical effect of anti-IFN- $\alpha$ on virus replication in leukocytes sensitive to viral infection may be attributed to changes in the cytokine profile balance, i.e. high TNF production by VSV-infected leukocytes and a complete reduction of IL-6 production.
\end{abstract}

Key words: cytokines, leukocytes, innate immunity, viral infection.

Corresponding author: Zofia Błach-Olszewska, Ph.D., Institute of Immunology and Experimental Therapy, Polish Academy of Sciences, R. Weigla 12, 53-114 Wrocław, Poland, tel.: +48 71 373-22-74, fax: + 4871 373-25-87, e-mail: blach@iitd.pan.wroc.pl

\section{INTRODUCTION}

Immune responses in vertebrates, invertebrates, and plants are initiated by the recognition of a large number of pathogens by cells of the innate immune system [2, 14]. In vertebrates, systemic reactions develop when the innate immune system is effectively activated. Phagocytosis with intracellular killing and the production and activity of cytokines such as interferons (IFNs), members of the tumor necrosis factor (TNF) superfamily, interleukins (IL-12, IL-18), chemokines, and adhesion molecules are very important. Another activity of the innate immune system is MHC-independent killing of infected cells by natural killer cells and by complement activated along the alternative or lectin pathways $[6,8,22,27]$. The resistance of cells, especially leukocytes ex vivo, to viral infections is also considered to be one of the reactions of innate immunity [2] which protect the host against invasion by microorganisms. As observed in many laboratories, high levels of cytokines with antiviral activity (IFNs and TNF) are frequently considered to be indicators of innate antiviral immunity. Our own results, obtained several years ago, showed different degrees of resistance to viral infection in organ 
cultures of human placenta, amniotic membrane, and umbilical cord vein [18, 29]. Resistance was directed against viruses belonging to different taxonomic groups: vesicular stomatitis virus (VSV, Rhabdoviridae), encephalomyocarditis virus (EMCV, Picornaviridae), and herpesvirus type 1 (Herpesviridae). Furthermore, resistance to different viral infections was found in cultures of murine and human leukocytes $[16,28]$. Therefore resistance is non-specific. It can be reduced by specific antibodies against IFN- $\alpha$, IFN- $\beta$, IFN- $\gamma$, and TNF- $\alpha$, which indicates a role of endogenous cytokines. Resistance is highest immediately after organ culture and leukocyte isolation and is reduced after 1-5 days of in vitro incubation before infection with virus. The non-specific character of antiviral immunity, its dependence on endogenous IFNs and TNF, and the fact that it is present in cells $e x$ vivo suggest that it could be considered innate immunity.

Using infection of peripheral blood leukocytes with VSV, we developed a new method for detecting innate immunity [16]. VSV was selected as an indicatory virus because it does not cause natural infections in the European human population, so specific antibodies against VSV are absent in human sera, which excludes the participation of acquired immunity in this experimental model of innate immunity. The virus also infects a wide spectrum of human and animal cells, including different types of immune cells. In our study, the whole peripheral blood mononuclear cell (PBMC) population was used, which mimics an in vivo natural system. Separated cell fractions are then needed for further studies. The results of preliminary experiments indicate that the innate immunity expressed by PMBCs is lower than that of the separate cell populations. These results suggest the presence of some regulatory mechanisms in PMBCs.

We used VSV replication in PBMCs to identify three different levels of natural immunity. A VSV replication titer higher than $4 \log \mathrm{TCID}_{50}$ was considered a deficiency of innate immunity, a titer of 2-3 log indicated partial resistance, and a titer of $0-1 \log$ indicated complete innate antiviral immunity. Using this method, we have studied the innate immunity of more than 300 people. Innate immunity was different among individuals. A lower level was often observed in persons with frequent infections of the upper respiratory track [16] and in those with frequent activation of herpes labialis. Deficiency of innate immunity is associated with the absence of remission and short survival time of patients with acute leukemia [4]. In contrast, all patients with complete immunity achieved long-lasting complete remission after chemotherapy and were still alive after finishing the study. An age dependence for immunity was also shown by Rybka et al. [21]. Leukocytes from the peripheral blood of healthy donors (30-40 years old) were mostly resistant to viral infection. In contrast, leukocytes isolated from cord blood vein and from elderly individuals $(>60)$ were vulnerable to viral infection. When innate immunity is over-stimulated, the reactions may lead to significant wastage in the body. Over-stimulation accompanies and participates in the development of autoimmunity or neurodegenerative diseases $[1,12,19,20,23,24]$. Therefore, innate reactions must be under rigorous control [3].

We decided to compare two evaluation methods of innate immunity: a direct method based on PMBC resistance to VSV infection and an indirect method based on cytokine secretion. The production of IFNs and of TNF- $\alpha$, IL-6, and IL-10 was studied. The role of every cytokine in innate immunity is different. The IFNs and TNF- $\alpha$ are the most important cytokines in antiviral immunity, IL-6, according to Jones [10], directs the transition from innate to acquired immunity, and IL-10 regulates immunity [15].

\section{MATERIALS AND METHODS}

\section{Blood donors samples}

Peripheral venous blood samples $(10 \mathrm{ml})$ were taken from a group of healthy volunteers (12 persons) and from currently healthy persons with recurrent infections of the upper respiratory tract (9 persons). The latter group was sent to a laboratory of virology to find the reason for their low immunity. The persons were $18-72$ years old.

The study was performed with permission of the local ethics committee.

\section{Cell cultures}

PMBCs were isolated from heparinized peripheral blood by gradient centrifugation in Dextran-Uropolin (Gradisol G) with a density of $1.115 \mathrm{~g} / \mathrm{ml}$ (Aqua Medica, Poznań, Poland). Five $\mathrm{ml}$ of blood were layered on $3 \mathrm{ml}$ of Gradisol and centrifuged for $25 \mathrm{~min}$ at $400 \mathrm{~g}$. Leukocytes from the border of the two phases were collected, washed two times with RPMI supplemented with $2 \%$ calf serum (CS), and suspended in the medium at a concentration of $2 \times 10^{6}$ cells $/ \mathrm{ml}$. The cell suspension was cultured at $37^{\circ} \mathrm{C}$ (in $5 \% \mathrm{CO}_{2}$ in air).

\section{$L_{929}$ cells (ATCC CCL 1)}

The murine fibroblast-like cell line was maintained in Eagle medium with $10 \% \mathrm{CS}$, antibiotics $(100 \mathrm{U} / \mathrm{ml}$ penicillin and $100 \mu \mathrm{g} / \mathrm{ml}$ streptomycin), and $2 \mathrm{mM} \mathrm{L-glutamine.}$

$A_{549}$ cells (ATCC CCL 185)

The human epithelial-like cell line was maintained in Dulbecco medium supplemented with $10 \%$ CS, antibiotics, and L-glutamine.

\section{Viruses}

VSV, Indiana strain, Rhabdoviridae, Vesiculovirus, was multiplied and titrated in $\mathrm{L}_{929}$ cells. EMCV, Columbia MM strain, Picornaviridae, Cardiovirus, was multiplied and titrated in $\mathrm{L}_{929}$ cells and used for IFN titration. 
Estimation of resistance/innate immunity of PBLs

Resistance/innate immunity was estimated by infection of leukocytes $\left(2 \times 10^{6} \mathrm{cells} / \mathrm{ml}\right)$ with VSV. They were infected with a dose of 100 TCID $_{50}$ (tissue culture infectious dose, based on the cytopathic effect caused by the virus in about $50 \%$ of infected $\mathrm{L}_{929}$ cells) of $\mathrm{VSV} / \mathrm{ml}$ of the leukocytes suspensions. After 40 min of adsorption, the virus was washed out three times with $5 \mathrm{ml}$ EMEM and the cells were suspended in $1 \mathrm{ml}$ RPMI with $2 \%$ CS. A sample of infected cells was kept at a temperature of $4^{\circ} \mathrm{C}$ and served as a control of the starting level of the virus. The other cells were incubated at $37^{\circ} \mathrm{C}$ and samples of medium above the infected cells were collected each day and titrated in $\mathrm{L}_{929}$. The titer of virus is expressed in $\mathrm{TCID}_{50}$. Based on the replication of VSV in PBMCs, we identified three different levels of natural antiviral immunity: a VSV replication titer higher than $4 \log \mathrm{TCID}_{50}$ was considered as deficiency of resistance/innate immunity, a titer of 2-3 log indicated partial resistance, and a titer of $0-1 \log$ indicated complete resistance/innate antiviral immunity.

\section{Cytokine assay}

IFN, TNF, and IL-6 were titrated using biological methods and IL-10 with ELISA.

IFN was titrated using the biological method of inhibition of the cytopathic effect caused by EMCV virus on the human cell line $\mathrm{A}_{549}$. In each experiment, calibration against an internal laboratory standard of human IFN- $\alpha / \beta$ was performed and the obtained results were corrected according to it. The internal standard was calibrated against the international standard of human leukocyte IFN 69/19.

TNF was assayed according to Flick and Gifford [7]. The cytotoxic activity of TNF- $\alpha$ in the samples was measured in $\mathrm{L}_{929}$ cells in the presence of actinomycin D (Serva, Germany) at a concentration of $2 \mu \mathrm{g} / \mathrm{ml}$ EMEM. Recombinant human TNF- $\alpha$ (Genetech, USA) was used as the standard in all assays. In our assay, 1 unit was equal to $2.5-10 \mathrm{pg} / \mathrm{ml}$ of TNF- $\alpha$.

Production of IL-6 was determined using the IL-6-dependent hybridoma cell line 7TD1 38 as previously described by Van Snick et al. [25]. Briefly, the cells were cultured in 96-well plates (Costar, MA, USA) at a concentration of $2 \times 10^{3}$ cells/well in the presence of serial dilutions of the supernatants from uninfected and VSV-infected leukocyte cultures. After $72 \mathrm{~h}$ the surviving cells were evaluated colorimetrically by staining the cells with 3-[4,5-dimethylthiazol-2-yl]-2,5-diphenyltetrazolium bromide (MTT, Sigma Chemicals Co., USA) and lysis of the cells with a sodium dodecyl sulfate (SDS)/ solution in a $45 \%$ aqueous solution (v/v) DMF (N, $\mathrm{N}$-dimethylformamide, Sigma Chemicals Co., USA). One unit of IL-6 activity was calculated as the inverse dilution of a supernatant sample in which a half-maximal proliferation of 7TD1 cells was registered. In our assay, one unit correspond to $0.1 \mathrm{ng}$ of recombinant $(E$. coli) human IL-6 (R\&D Systems, USA). The sensitivity of the bioassay was $5 \mathrm{U} / \mathrm{ml}$.

IL-10 was quantified using ELISA according to the producer's instructions (BD Bioscientes Pharmingen, USA).

\section{Antibodies against human cytokines}

Anti-IFN- $\alpha$ (polyclonal, sheep), anti-IFN- $\gamma$ (polyclonal, goat), and anti-TNF- $\alpha$ (polyclonal, rabbit) antibodies were from Sigma-Aldrich (St. Louis, MO, USA) and anti-IFN- $\beta$ (polyclonal, sheep) from the National Institutes of Health (Bethesda, MD, USA).

\section{Statistical analysis}

The data were presented as means, standard deviations (SD), medians, quartiles (25-75\%), and ranges (min.-max.). The significance of differences between groups was determined using the Student's $t$-test and the Mann-Whitney U-test. Differences between pairs of measurements in the same patients were tested using Wilcoxon's matched-pairs signed-ranks test. Spearman's rank correlation test was used for determining the relationship between the levels of IL- 6 and the concentration of anti-IFN. The analysis was done using the computer program Statistica Version 5.1, Stat-Soft (USA), taking $\mathrm{p}<0.05$ as statistically significant.

\section{RESULTS}

Human leukocytes present different levels of antiviral immunity (cytokine production and resistance to viral infection)

In our study we used leukocytes isolated from the peripheral blood of 21 currently healthy persons with different innate immunity. The cultures of leukocytes were infected with VSV $\left(100 \mathrm{TCID}_{50} \mathrm{ml}\right)$ immediately after preparation $(T=0)$ and the kinetics of virus replication was studied during three days of infection. The results obtained are presented in Fig. 1. The kinetics of VSV replication was different, so two groups of individuals were distinguished. The first consisted of 7 persons with resistant to viral infection leukocytes. They had very low or no viral replication $\left(0-1 \log \mathrm{TCID}_{50}\right)$. The second group consisted of 14 persons ( 9 from the group with frequent infections and 6 healthy blood donors) with partial immunity or no resistance. VSV replicated to a titer of $2-5 \log$.

In the next experiments, spontaneous and VSV-induced cytokine production in both groups (resistant and sensitive PMBCs) were measured. We found that VSV infection only stimulated IFN production, did not significantly influence TNF, and reduced IL- 6 and IL-10 levels.

To determine the correlation between the level of resistance/innate immunity measured by VSV replica- 


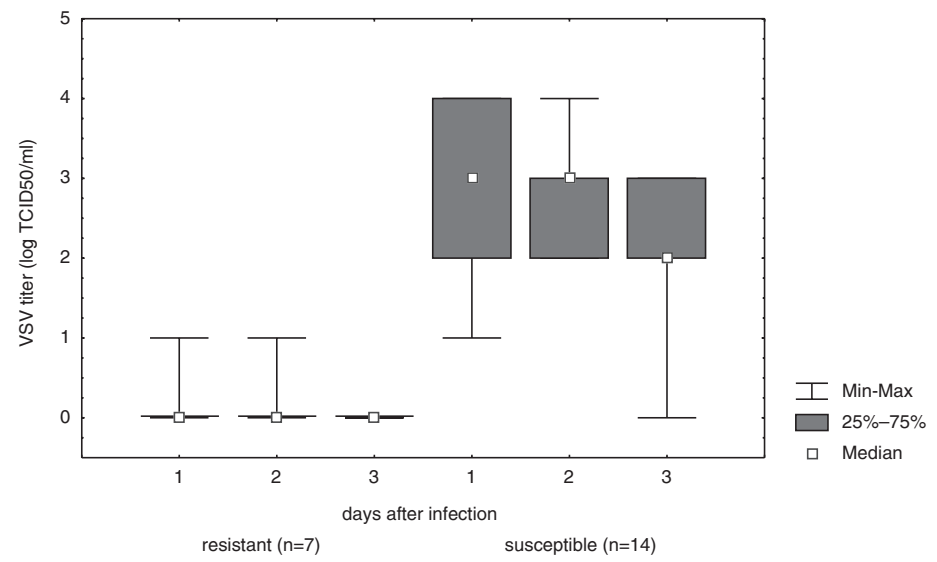

Fig. 1. Kinetics of VSV replication in human PMBCs $(n=21)$. Leukocytes were infected with VSV immediately after their isolation, washed several times with culture medium, and incubated at $37^{\circ} \mathrm{C}$ for 3 days. The kinetics of virus replication was studied in samples collected each day after infection. The samples were titrated in $\mathrm{L}_{929}$ cells.

tion and the production of cytokines, we monitored the levels of IL-6, IL-10, TNF, and IFNs in the supernatants of two different leukocyte cultures, uninfected and after infection with VSV. Leukocytes with stronger resistance/innate immunity produced more cytokines; how- ever, statistical significance was found only in the case of VSV-induced IFN. Figure 2 presents a comparison of spontaneous cytokine production by leukocytes with high and low levels of resistance/innate antiviral immunity.

\section{Elimination of IFN- $\alpha$ caused an unexpected reduction in VSV replication in sensitive leukocytes and a disturbance in cytokine production}

In the next experiment the influence of specific anti-IFNs and anti-TNF- $\alpha$ antibodies on VSV replication and the production of cytokines by leukocytes with different antiviral immunity was examined. Before their application, the antibodies were carefully titrated for effective neutralization. The amounts were sufficient to neutralize cytokines produced by leukocytes. The antibodies were added to the leukocytes after VSV adsorption. The antibodies stimulated viral replication in the virus-resistant cells (results not shown). This effect indicates that endogenous IFNs and TNF- $\alpha$ participate in the maintenance of resistance/innate immunity. The influence of the antibodies on viral replication in leukocytes sensitive to VSV infection is presented in Fig. 3. Instead of the expected stimulation of virus replication after endogenous IFN- $\alpha$ elimination, a reduction in virus titer was observed. We attempted to explain these
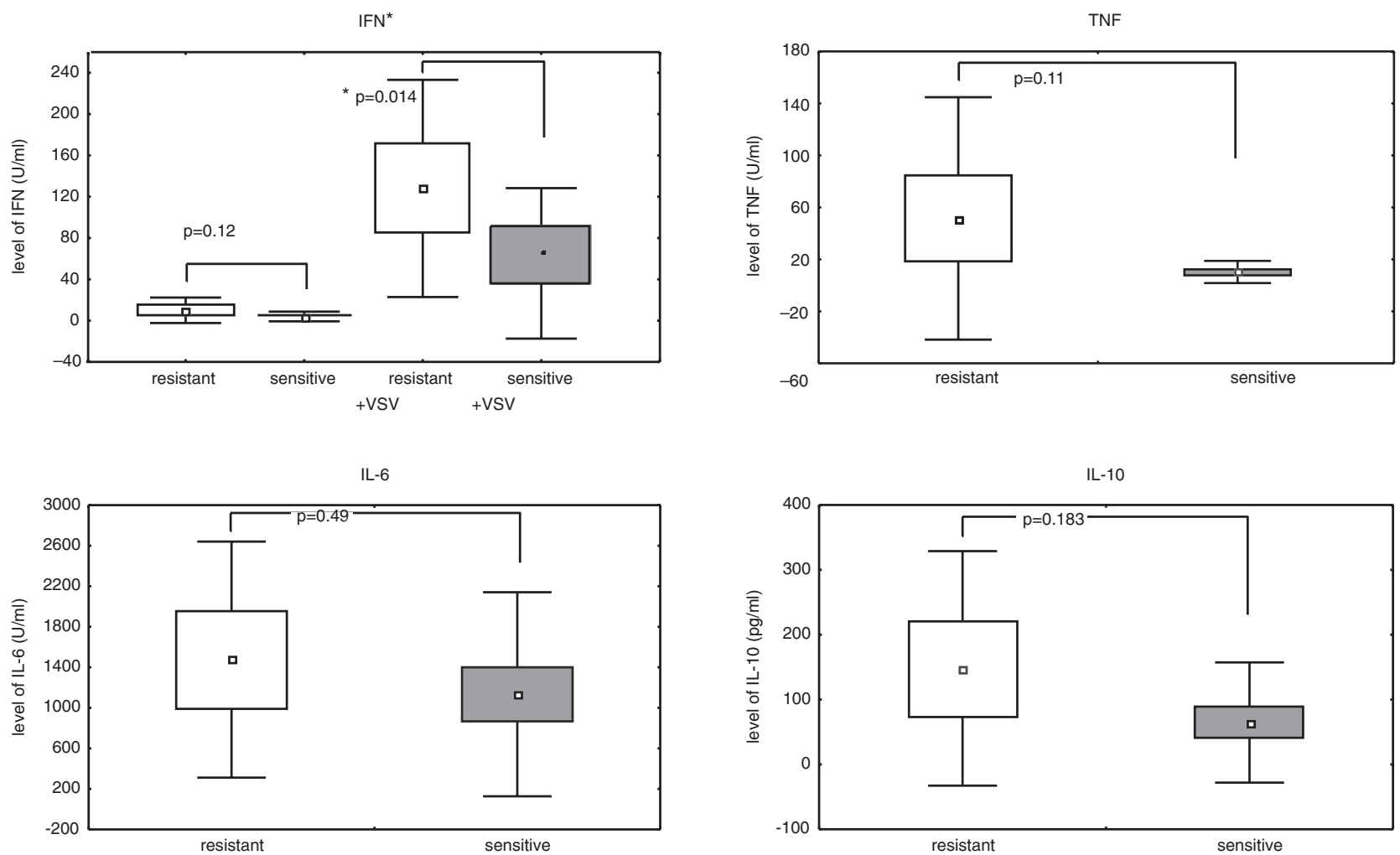

Fig. 2. Comparison of spontaneous production of cytokines by VSV-resistant $(n=7)$ and VSV-sensitive $(n=14)$ PMBCs. The samples were collected after $24 \mathrm{~h}$ of cell incubation from uninfected and VSV-infected PMBCs. In the figure, however, spontaneously released cytokines are presented. Only the IFN level is presented in both the uninfected and VSV-infected PMBCs. To inactivate the virus, the samples of VSV-infected cells were UV irradiated (on ice) before titration. IFN, TNF, and IL-6 were titrated by biologic methods and IL-10 by ELISA. Statistics were performed using the Student's $t$-test. *Statistically significant. 


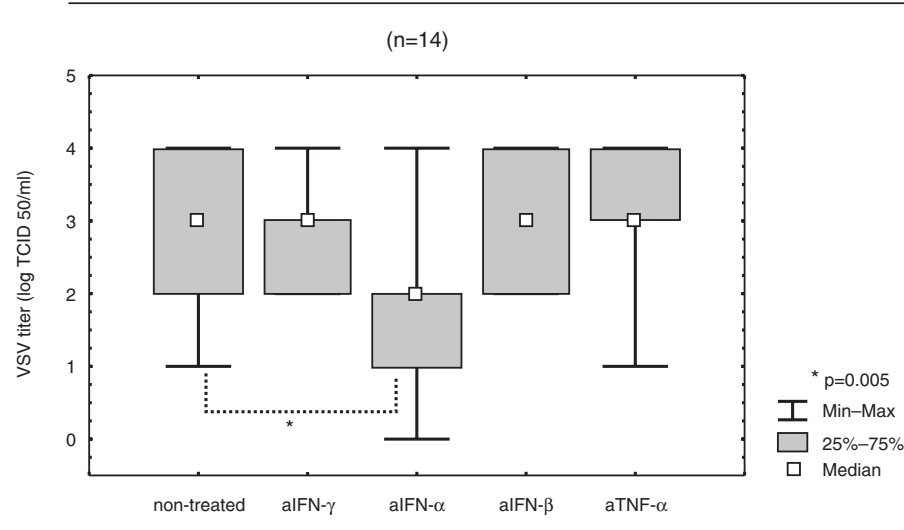

Fig. 3. Effect of anti-IFNs and anti-TNF- $\alpha$ antibodies on VSV replication in PMBCs sensitive to VSV infection. The antibodies $(\mathrm{a}=$ anti) were applied to VSV-infected PMBCs after virus adsorption. The kinetics of viral replication in antibody-treated cells was compared with untreated cells. Samples of media were collected over three days. VSV was titrated in each sample in $\mathrm{L}_{929}$ cells. Results from the first day after VSV infection are presented. Statistics were performed using the Mann-Whitney test. *Statistically significant.
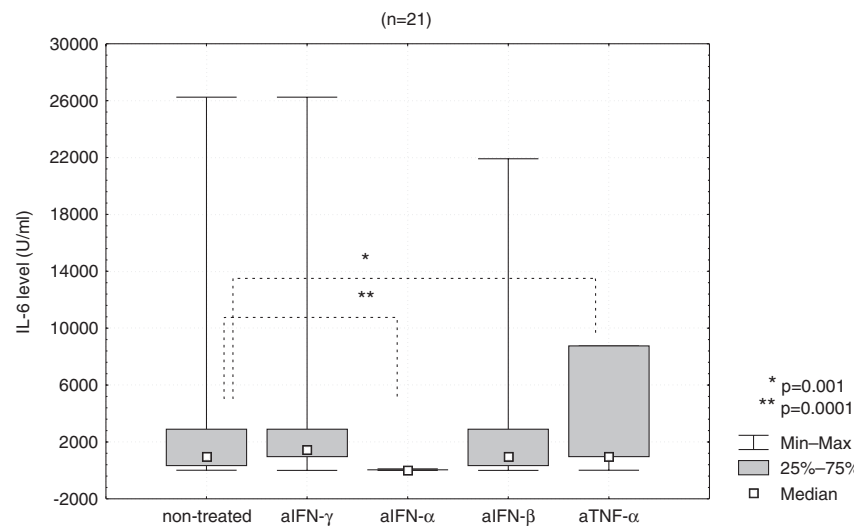

Fig. 4. Effect of antibodies against IFNs and TNF on IL-6 production by PBLs. Anti-cytokines antibodies $(\mathrm{a}=\mathrm{anti})$ were added immediately after virus adsorption. The level of IL-6 was determined in sensitive and resistant PMBCs. Statistics were performed with the non-parametric Wilcoxon test. *,**Statistically significant.

unexpected results by studying changes in cytokine profiles in the absence of endogenous IFNs and TNF- $\alpha$. It was found that in the absence of endogenous IFN- $\alpha$ the profile of cytokine production was changed. The presence of anti-IFN- $\alpha$ antibodies abolished IL- 6 production. The lack of IL- 6 production was observed in both resistant and sensitive leukocytes, infected as well as uninfected. The results of IL-6 production by uninfected untreated leukocytes and those treated with anti-IFNs and anti-TNF- $\alpha$ antibodies are presented in Fig. 4. The other important observation was that in the presence of anti-IFN- $\alpha$ antibodies, an increased level of TNF- $\alpha$, remarkably so in infected leukocytes from the VSV-sensitive group, was observed (Fig. 5). To confirm the possible role of TNF in antiviral activity, VSV-

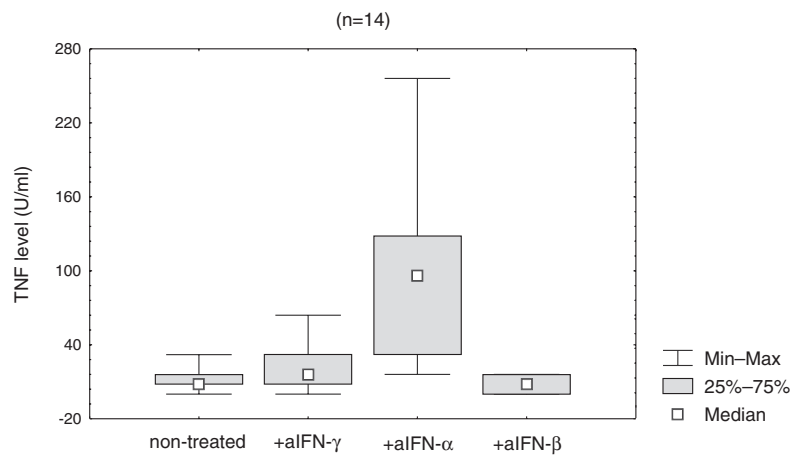

Fig. 5. Effect of anti-IFNs antibodies on TNF production in sensitive leukocytes infected with VSV. For description, see Fig 4. $*, * *$ Statistically significant.

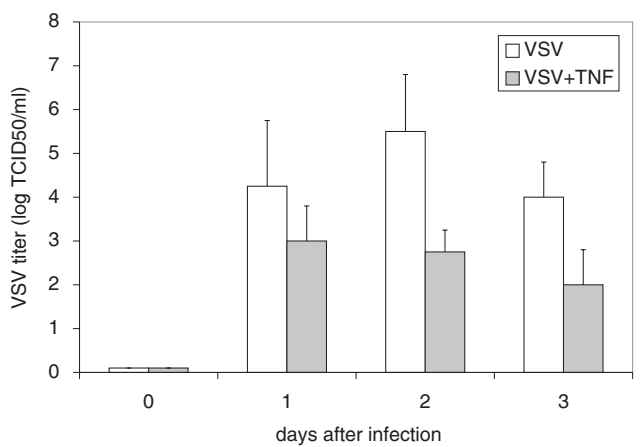

Fig. 6. Effect of TNF- $\alpha$ on VSV replication in sensitive leukocytes $(n=4) .100 \mathrm{U}$ of TNF- $\alpha$ was added to the leukocytes just after VSV adsorption and the kinetics of virus replication was studied.

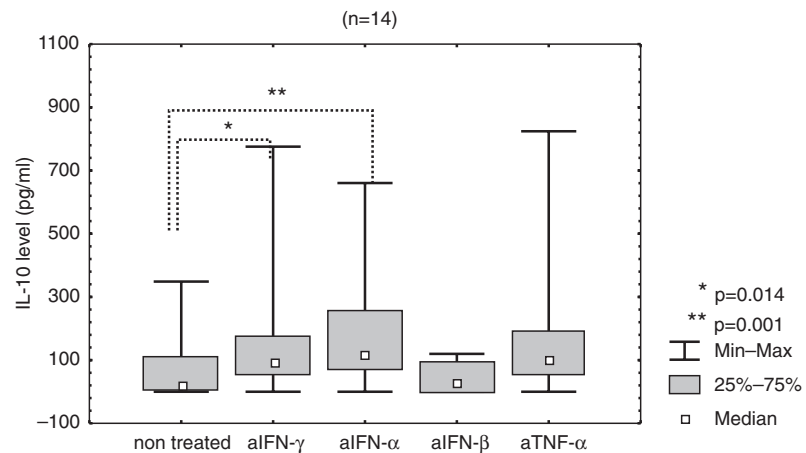

Fig. 7. Effect of the elimination of endogenous IFNs and TNF- $\alpha$ on IL-10 production in sensitive leukocytes infected with VSV. For description, see Fig $4 .{ }^{*}, * *$ Statistically significant.

-infected leukocytes sensitive to the virus were treated with $100 \mathrm{U}$ of TNF- $\alpha$ (the median TNF level in leukocytes treated with antibody against IFN- $\alpha$ ). The results of four independent experiments, presented in Fig. 6, show a reduction in VSV titer by $2-4 \log$.

The antibodies against IFN- $\alpha$ also stimulated IL-10 production depending on the level of innate immunity level (Fig. 7). The addition of antibodies against TNF- $\alpha$ 
did not markedly influence IFN production (data not shown).

The results indicated that the elimination of endogenous IFN- $\alpha$ caused the largest changes in cytokine profiles. The changes involving TNF- $\alpha$ production were suspected to be responsible for the unexpected inhibition of virus replication by the antibodies. To prove the hypothesis, we tried to reduce the antiviral effect of the anti-IFN- $\alpha$ antibodies with addition anti-TNF- $\alpha$. The results of the experiments were, however, unclear, suggesting that not only TNF, but other unknown mediators might participate in the antiviral effect.

\section{DISCUSSION}

In view of cytokines' antiviral activity, the question arises whether PMBCs (resistant or sensitive to VSV) expressing high, non-specific, antiviral resistance/innate immunity are able to produce more cytokines than those expressing low innate immunity. In this context we studied the production of IFN, TNF, IL-6, and IL-10. The results of this study show differences in cytokine production by cells with different degree of resistance/innate immunity. VSV-resistant PMBCs with good innate immunity released more spontaneous cytokines than PMBCs with immune deficiency. Statistical significance, however, was found only in the case of VSV-induced IFN. This means that even though the cells were not able to replicate VSV to a high level, they were able to produce more IFN after contact with VSV than the sensitive cells with high titers of VSV.

The results of a previous study on the influence of specific anti-cytokine antibodies on viral replication in human leukocytes revealed the importance of endogenous IFNs and TNF- $\alpha$ in maintaining antiviral innate immunity [16]. Specific antibodies against IFN- $\alpha$, IFN$-\beta$, IFN- $\gamma$, and TNF- $\alpha$ caused reductions in innate immunity, mimicking the phenomenon observed after stimulation of viral replication in PMBCs previously resistant to VSV. Quite different results were obtained when antibodies, especially antibodies against IFN- $\alpha$, were added to cells with very low innate immunity. Instead of VSV stimulation, reduction of VSV replication was observed. We tried to find the reason for these unexpected results. As first, a possible disturbance in cytokine production and replacement of antiviral function of IFN by other cytokines was considered. In fact, neutralization of IFN- $\alpha$ with specific antibodies caused a disturbance in leukocyte cytokine profiles. In the absence of endogenous IFN- $\alpha$ production, IL- 6 was completely abolished. The other consequence of IFN- $\alpha$ elimination was stimulation of TNF- $\alpha$. This higher TNF- $\alpha$ production by infected leukocytes sensitive to viral infection was assumed to be probably the reason for this paradoxical inhibition of VSV replication. Within the group deficient in innate immunity, TNF- $\alpha$ may show an inhibitory effect on viral replication.

Antiviral activity of TNF- $\alpha$ has been reported by dif- ferent authors [11, 13, 26]. For example, Mestan et al. [13] showed that recombinant TNF- $\alpha$ added to the Hep-2 cell line protects the cells against VSV infection. This effect was specific for TNF because the antiviral activity was abolished by anti-TNF, but not by anti-IFN- $\alpha$ antibodies This observation is in agreement with our results obtained in VSV-sensitive PBLs. In our previous study, however, TNF- $\alpha$ 's effect on VSV replication was dependent on the innate immunity of the PMBCs [16]. In sensitive cells, an inhibitory effect on viral replication was observed, while in resistant PMBCs a stimulation of VSV replication. In embryonal tissues sensitive to VSV, inhibition of viral replication was also observed [17]. Inhibition of viral replication by TNF in sensitive leukocytes was shown in this study. In cultures resistant to infection, the opposite effect and stimulation of replication occurred [18]. Similarly, effects depending on the level of innate immunity were noticed following culture treatments with immunomodulating substances, i.e. lipopolysaccharide and peptides from ovine colostrums $[5,9]$. The virus stimulatory effect, however, was eliminated by antibodies against TNF- $\alpha$. Our previous and the present study indicate a double role of endogenous TNF- $\alpha$ : it is responsible for both inhibition and stimulation of viral replication by immunomodulators. The lack of IL- 6 production in the absence of IFN- $\alpha$ indicates the necessity for this type of IFN for IL-6 production by leukocytes. Over the years, IL-6 has been assigned both pro- and anti-inflammatory properties. According to Jones [10], an important role of IL-6 is directing the transition from innate to acquired immunity; IFN- $\alpha$, through its effect on IL-6 production, could thus indirectly influence this transition.

Acknowledgment: We are grateful to Prof. Maria Janusz for critical discussions during the preparation of this manuscript. This work was supported by the State Committee for Scientific Research (KBN, Poland), grant no. 6P05 AA 038 20, and the Foundation for Polish Science, grant IMMUNO no. 9.

\section{REFERENCES}

1. Baccala R., Kono D. H. and Theofilopoulos A. N. (2005): Interferons as pathogenic effectors in autoimmunity. Immunol. Rev., 204, 9-26.

2. Błach-Olszewska Z. (2005): Innate immunity: cells, receptors and signaling pathway. Arch. Immunol. Ther. Exp., 53, 245-253.

3. Błach-Olszewska Z. (2006): Mechanizmy kontroli odporności wrodzonej [Control of over-activated innate immunity]. Postępy Hig. Med. Dośw., 60, 201-208.

4. Błach-Olszewska Z., Zaczyńska E., Kiełbiński M. and Frydecka I. (2005): Deficiency of innate immunity of leukocytes is associated with the failure of the induction of remission and survival time in patients with acute leukemia. Pol. J. Environmental Studies, 14 (suppl. II), $36-40$

5. Domaraczenko B., Janusz M., Orzechowska B., Jarosz W. and Błach-Olszewska Z. (1999): Effect of proline rich polypeptide from ovine colostrum on virus replication in human placenta and amniotic membrane at term; possible 
role of endogenous tumor necrosis factor. Placenta, 20, 695-701.

6. Ferlazzo G. and Munz C. (2004): NK cell compartments and their activation by dendritic cells. J. Immunol., 172, 133.3-1339.

7. Flick D. A. and Gifford G. E. (1984): Comparison of in vitro cell cytotoxic assays for tumor necrosis factor. J. Immunol. Methods, 68, 167-171.

8. Fujita T., Matsushita M. and Endo Y. (2004): The lectincomplement pathway - its role in innate immunity and evolution. Immunol. Rev., 198, 185-202.

9. Jatczak B., Gejdel E., Pająk J., Podwińska J. and BłachOlszewska Z. (2001): Study on risk factors for transplacental viral infections; effect of bacterial factors and double viral infections on virus replication in placenta and amniotic membranes. Placenta, 22, 360-371.

10. Jones S. A. (2005): Directing transition from innate to acquired immunity: defining a role for IL-6. J. Immunol., 175, 3463-3468.

11. Lane B. R., Markovitz D. M., Woodford N. L., Rochford R., Strieter R. M. and Coffey M. J. (1999): TNF-alpha inhibits HIV-1 replication in peripheral blood monocytes and alveolar macrophages by inducing the production of RANTES and decreasing $\mathrm{C}-\mathrm{C}$ chemokine receptor 5 (CCR5) expression. J. Immunol., 163, 3653-3661.

12. Lehnardt S., Massillon L., Follett P., Jensen F. E., Ratan R., Rosenberg P. A., Volpe J. J. and Vartanian T. (2003): Activation of innate immunity in the CNS triggers neurodegeneration through a Toll-like receptor 4-dependent pathway. Proc. Natl. Acad. Sci. USA, 100, 8514-8519

13. Mestan J., Digel W., Mittnacht S., Hillen H., Blohm D., Moller A., Jacobsen H. and Kirchner H. (1986): Antiviral effect of recombinant tumour necrosis factor in vitro. Nature, 323, 816-819.

14. Miedzhitow R. and Biron C. A. (2003): Innate immunity. Curr. Opin. Immunol., 15, 2-4.

15. Murray P. J. (2005): The primary mechanism of the IL-10-regulated antiinflammatory response is to selectively inhibit transcription. Proc. Natl. Acad. Sci. USA, 102, 8686-8691.

16. Orzechowska B., Antoszków Z., Siemieniec I. and Błach-Olszewska Z. (2003): Individual differentiation of innate antiviral immunity in humans; the role of endogenous interferons and tumour necrosis factor in the immunity of leukocytes Arch. Immunol. Ther. Exp., 51, 51-60.

17. Paradowska E., Błach-Olszewska Z., Gierlińska M. and Woytoń J. (1996): Effect of exogenous tumor necrosis factor, interleukin 6 , and interferons on vesicular stomatitis virus replication in human placenta and amniotic membrane organ cultures. Arch. Immunol. Ther. Exp., 44, 57-62.

18. Paradowska E., Błach-Olszewska Z., Sender J. and Jarosz
W. (1996): Antiviral nonspecific immunity. Possible role of endogenous tumor necrosis factor and interferons. J. Interferon Cytokines Res., 16, 941-947.

19. Poea-Guyon S., Christadoss P., Le Panse R., Guyon T., De Baets M., Wakkach A., Bidault J., Tzartos S. and Berrih-Aknin S. (2005): Effects of cytokines on acetylcholine receptor expression: implications for myasthenia gravis. J. Immunol., 174, 5941-5949.

20. Rifkin I. R., Leadbetter E. A., Busconi L., Viglianti G. and Marshak-Rothstein A. (2005): Toll-like receptors, endogenous ligands, and systemic autoimmune disease. Immunol. Rev., 204, 27-42.

21. Rybka K., Orzechowska B., Siemieniec I., Leszek J., Zaczyńska E., Pająk J. and Błach-Olszewska Z. (2003): Age related natural antiviral non-specific immunity of human leukocytes. Med. Sci. Monit., 9, BR413-417.

22. Selander B., Martensson U., Weintraub A., Holmstrom E., Matsushita M., Thiel S., Jensenius J. C., Truedsson L. and Sjoholm A. G. (2006): Mannan-binding lectin activates C3 and the alternative complement pathway without involvement of C2. J. Clin. Invest., 116, 1425-1434.

23. Tanga F. Y., Nutile-McMenemy N. and DeLeo J. A. (2005): The CNS role of Toll-like receptor 4 in innate neuroimmunity and painful neuropathy. Proc. Natl. Acad. Sci. USA, 102, 5856-5861.

24. Townsend K. P., Town T., Mori T., Lue L. F., Shytle D., Sanberg P.R., Morgan D., Fernandez F., Flavell R. A. and Tan J. (2005): CD40 signaling regulates innate and adaptive activation of microglia in response to amyloid $\beta$-peptide. Eur. J. Immunol., 35, 901-910.

25. Van Snick J., Cayphas S., Vink A., Uyttenhove C., Coulie P. G., Rubira M. R. and Simpson R. J. (1986): Purification and $\mathrm{NH}_{2}$-terminal amino acid sequence of a $\mathrm{T}$ -cell-derived lymphokine with growth factor activity for B-cell hybridomas. Proc. Natl. Acad. Sci. USA, 83, 9679-9683.

26. Wong G. H., Kamb A. and Goeddel D. V. (1992): Antiviral properties of TNF. In Buetler B (ed.): Tumor necrosis factor: the molecules and their emerging role in medicine. Raven Press Ltd., New York, pp. 371-382.

27. Yuste J., Ali S., Sriskadan S., Hyams C., Botto M. and Brown J. S. (2006): Roles of the alternative complement pathway and C1q during innate immunity to Streptococcus pyogenes. J. Immunol., 176, 6112-6120.

28. Zaczyńska E. and Błach-Olszewska Z. (2001): Effect of cyclosporine $A$ on the non-specific innate immunity of mice. Arch. Immunol Ther Exp., 49 (suppl.), S53-S57.

29. Zaczyńska E., Błach-Olszewska Z. and Gejdel E. (1995): Production of cytokines with antiviral activity by endothelial cells. J. Interferon Cytokine Res., 15, 811-814. 
